\title{
TPGS-Modified Long-Circulating Liposomes Loading Ziyuglycoside I for Enhanced Therapy of Myelosuppression
}

\section{Tingting Song* \\ Hong Wang* \\ Yue Liu \\ Rongshan Cai \\ Dezhi Yang \\ Yongai Xiong}

Department of Pharmacy, Zunyi Medical University, Zunyi City, People's Republic of China

*These authors contributed equally to this work
Correspondence: Yongai Xiong

Email yaxiong@zmu.edu.cn
Background: Ziyuglycoside I ( $\mathrm{ZgI})$, an active ingredient isolated from traditional Chinese medicine Sanguisorba officinalis L, has been demonstrated to increase the leucocytes and protect hematopoietic stem cells. However, the poor solubility and a short half-life of $\mathrm{ZgI}$ limit its bioavailability and efficacy. The D- $\alpha$-tocopherol polyethylene glycol 1000 succinate (TPGS) has been widely used to increase the solubility, improve the encapsulation rate, and extend the half-life of drugs.

Methods: Here, we formulated the TPGS-modified long-circulating liposomes loading ZgI with a sustained drug release and enhanced therapy for myelosuppression. ZgI-TPGS-liposomes were manufactured using a thin-film hydration technique, followed by characterizations of physicochemical properties, including the particle size, zeta potential, TEM, SEM, FTIR, XRD, stability, drug loading (DL), encapsulation efficiency (EE). The in vitro and in vivo delivery efficiency were further evaluated by cellular uptake, in vitro drug release and in vivo pharmacokinetics. Finally, therapeutic effect on myelosuppression was investigated.

Results: The ZgI-TPGS-liposomes had an particle size of $97.89 \pm 1.42 \mathrm{~nm}$ and ZP of -28.65 $\pm 0.16 \mathrm{mV}$. It exhibited DL of $9.06 \pm 0.76 \%$ and $\mathrm{EE}$ of $92.34 \pm 3.83 \%$, along with excellent storage stability, cellular uptake and sustained drug release to free $\mathrm{ZgI}$ and liposomes without TPGS. Additionally, the TPGS modified liposomes significantly enhanced the therapeutic effect of ZgI on CTX induced myelosuppression, which can be confirmed in the apoptosis inhibition and cell viability promotion of CTX injured HSPC-1 cells. Also, the mice in vivo pharmacodynamics demonstrated that TPGS liposomes promoted ZgI increasing the numbers of leucocytes and neutrophils in myelosuppression mice induced by CTX.

Conclusion: Our research suggest that TPGS-modified long-circulating liposomes loading ziyuglycoside I has potential application in myelosuppression therapy.

Keywords: myelosuppression, therapy, TPGS, long-circulating liposomes, ziyuglycoside I

\section{Introduction}

The radiotherapy and chemotherapy are still the main therapies for cancer. During the treatment, the cancer patients usually undergo multiple cycles of radiotherapy or are given high-dose chemotherapy agents, such as the cyclophosphamide, fluorouracil and doxorubicin to kill the tenacious cancer cells. ${ }^{1,2}$ However, the radioactive rays and chemotherapy agents have serious toxic effects on the human body, including the immunosuppression, gastrointestinal toxicity, myelosuppression and the viscera toxicity, bringing great pain and heavy economic burden to patients, ${ }^{3}$ which has become a fatal obstacle to the further treatment for cancer patients. ${ }^{4}$ 
The myelosuppression is the most serious side effects caused by radiotherapy and chemotherapy, which is generally characterized by the decline of the hemocytes in peripheral blood, including the leucocyte, erythrocyte, platelet and neutrophil counts, which often leads to the infection, bleeding, or anemia in cancer patients. ${ }^{5,6}$ The myelosuppression firstly manifests as the leucocytes decrease, causing patients high fever and infection and treatment interruption, which seriously affects the life quality of patients and treatment process. ${ }^{7}$

The hemocytes of peripheral blood are derived from the proliferation and differentiation of hematopoietic stem cells (HSCs) in the bone marrow. ${ }^{8,9}$ The HSCs damage caused by radiation and chemotherapeutic drugs is the essential cause of leucocytes decline. Therefore, how to effectively protect the HSCs and restore its hematopoietic function is vital for cancer patients.

The Sanguisorba officinalis L (Figure 1), a traditional Chinese medicine which has been used in China for nearly 1000 years, has wide pharmacological activities including hemostasis, antidiarrheal, antineoplastic and increasing leucocytes. ${ }^{10}$ The Sanguisorba officinalis is only needed $5 \mathrm{mg}$ to treat leukopenia. Our previous study has confirmed that the Ziyuglycoside I ( $\mathrm{ZgI}$ ) (Figure 1) is the crucial component of the Sanguisorba officinalis, which has prominent activity to increase the leucocytes. ${ }^{11}$ What's the most important, $\mathrm{ZgI}$ can protect HSCs from apoptosis induced by chemotherapy agents. ${ }^{12}$

The $\mathrm{ZgI}$ belongs to ursane type pentacyclic triterpene saponin, and it's classed to be the IV drug in the Biopharmaceutical Classification System (BCS). In the previous study, we have proved that the $\mathrm{ZgI}$ has poor solubility and a short half-life in vivo, which limits its bioavailability and efficacy. ${ }^{13}$ The TPGS is a polyethylene glycol (PEG) derivative of vitamin $\mathrm{E}$ succinate. It is composed of a hydrophilic group PEG and a lipophilic group tocopheryl succinate with HLB value of 13.2, showing an excellent water solubility. ${ }^{14,15}$ The TPGS has been widely used to increase the solubility of hydrophobic drugs, improve the encapsulation rate of drugs, and extend the half-life of drugs. ${ }^{16,17}$ In this paper, the $\mathrm{ZgI}$ was firstly loaded in liposomes (ZgI-liposomes), then the ZgI-liposomes were coated by TPGS (ZgI-TPGS-liposomes), as is shown in Figure 2. This study aimed to compare the drug release, cellular uptake, pharmacokinetic parameters and effectiveness of ZgI-TPGS-liposomes with free $\mathrm{ZgI}$ and $\mathrm{ZgI}-$-liposomes.

\section{Materials, Cell Lines, and Animals}

Ziyuglycoside I was purchased from MUST Biotech Co, Ltd. (Chengdu, China). Phosphatidylcholine was purchased from Lipoid Co, Ltd. (German). TPGS (D- $\alpha-$ tocopherol polyethylene glycol 1000 succinate), Vitamin E, coumarin 6 (C-6), and DAPI were obtained from Aladdin reagent Co, Ltd. (Shanghai, China). The FBS and DMEM high-sugar medium were purchased from Gibco (USA). RPMI-1640 and CCK-8 were purchased from Procell Life Science \& Technology Co., Ltd (Wuhan, China). Tunel Apoptosis Detection Kit was purchased from Boster Biological Technology Co. Ltd (USA). Cyclophosphamide (CTX) and G-CSF were kindly provided by Affiliated Hospital of Zunyi Medical University.

Human hematopoietic stem cells (HSPC-1) and RAW264.7 cells were kindly provided by Procell Life Science \& Technology Co., Ltd (Wuhan, China).

Specified pathogen-free (SPF) male and female KM mice $(20 \pm 2 \mathrm{~g})$ and SD rats $(200 \pm 20 \mathrm{~g})$ were purchased
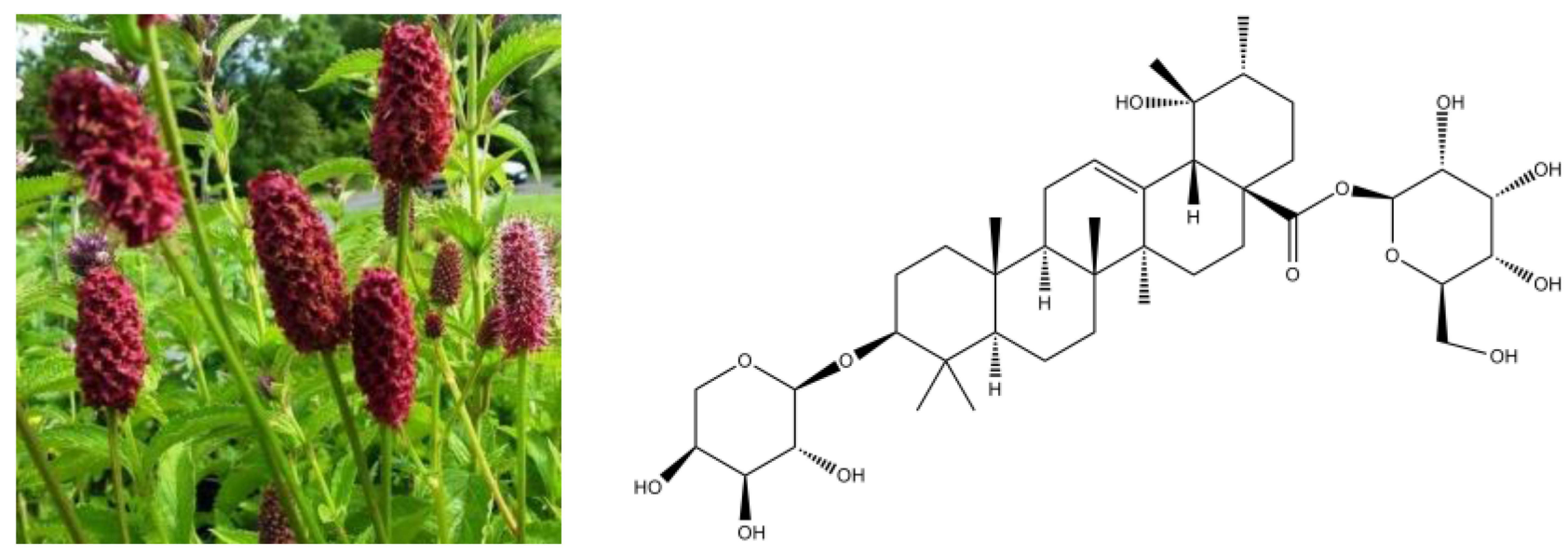

Figure I The Sanguisorba officinalis and the molecule structure of Ziyuglycosidel. 


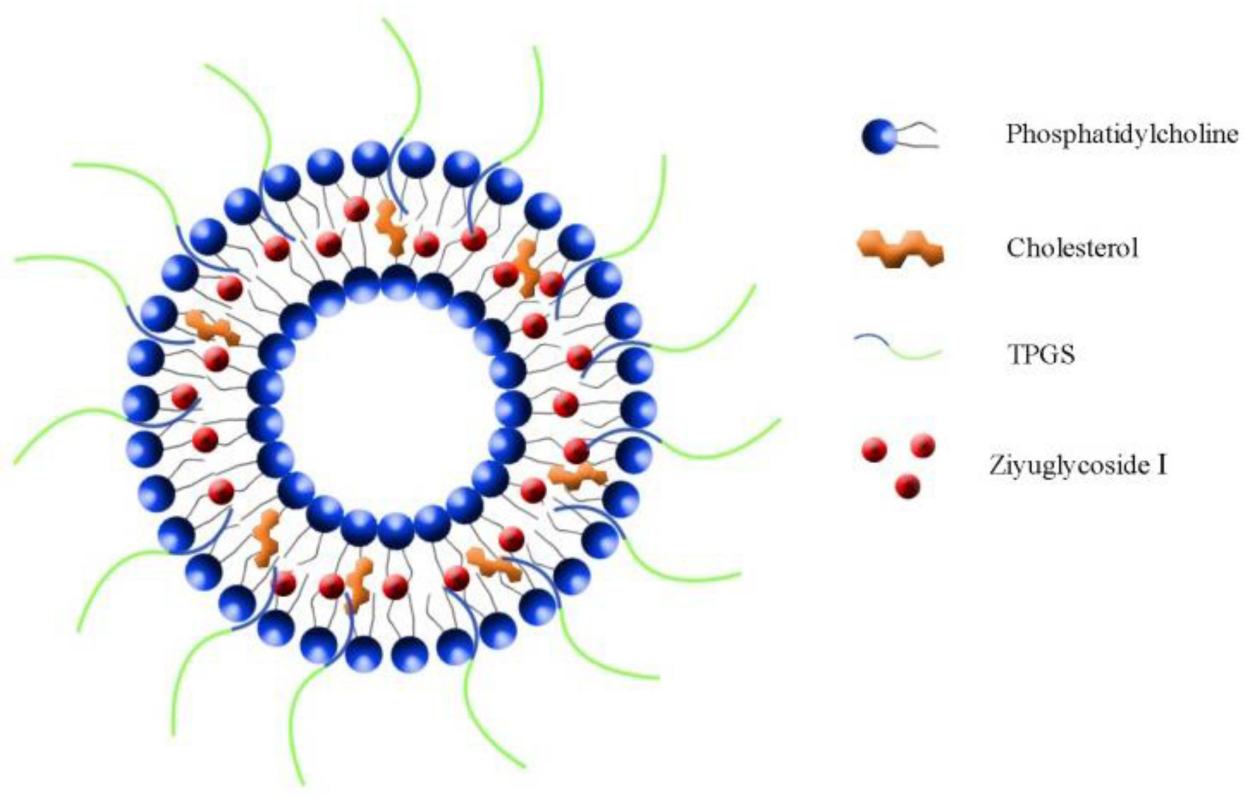

Figure 2 Preparation scheme of Zgl-TPGS-liposomes.

from Tianqing Biotechnology Co., Ltd of Changsha (Changsha, China). Animals were housed in a SPF facility containing standard bedding with 12 -h light-dark cycles ( 7 to $19 \mathrm{~h}$, temperature $\left(22 \pm 2{ }^{\circ} \mathrm{C}\right)$, humidity $(40-70 \%)$, controlled ventilation) and fed with standard irradiated pellet food and sterile water ad libitum. All of the animal experimental protocols were approved by the Ethics Committee of Zunyi Medical University. All animal care and experimental procedures were performed in accordance with the Laboratory Animal Welfare and Ethics Committee of China.

\section{Preparation of Zgl-TPGS-Liposomes}

The thin-film dispersion method was used to prepare the ZgI-liposomes and ZgI-TPGS-liposomes. Briefly, 30 g phosphatidylcholine, 6 g cholesterol, 2 g Ziyuglycoside $\mathrm{I}$ and $1 \mathrm{~g}$ Vitamin $\mathrm{E}$ were dissolved in a mixed solvent of chloroform-methanol (2: $1, \mathrm{v} / \mathrm{v})$ by ultrasound. Then the TPGS was added at mole percentage of $7.8 \%(1.15 \mathrm{~g})$. Here, the mole percentage means the mole amount of TPGS which accounts for $7.8 \%$ of that of phosphatidylcholine. The dissolution was carried out in an eggplantshaped bottle. When the clear solution was obtained, the chloroform and methanol were recycled by rotary evaporator. Then, an uniform and transparent lipid film could be seen at the bottom of the eggplant-shaped bottle. $5 \mathrm{~mL}$ phosphate buffer solution ( $\mathrm{pH}$ 7.4) was added and hydrated $2 \mathrm{~h}$ at $37^{\circ} \mathrm{C}$. Then, the probe sonicator (TL-
650Y, Tianling Instrument Co., Ltd., Jiangsu, China) was used to reduce the particle size of hydrates. Finally, the ZgI-TPGS-liposomes was obtained and it was an opalescent solution with blue light. The samples were stored in a refrigerator at $4^{\circ} \mathrm{C}$. The C-6 liposomes, which was used to test cellular uptake, were also prepared using the mentioned method.

\section{Characterization of Zgl-TPGS-Liposomes}

The particle size and zeta potential of ZgI-TPGSliposomes were measured using laser particle analyzer (90Plus PALS, BrookHavenin, USA) at a room temperature $\left(25^{\circ} \mathrm{C}\right)$. Samples were tenfold diluted with phosphate buffer solution $(\mathrm{pH}=7.4)$ before the measurements. The morphology of ZgI-TPGS-liposomes was detected by Transmission Electron Microscope (TEM, JEM2100Plus; JEOL, Japan) and Scanning Electron Microscope (SEM, SU3900; HITACHI, Japan), respectively.

The drug loading (DL) and encapsulation efficiency (EE) of ZgI-TPGS-liposomes were determined by ultrafiltration centrifugation method. ${ }^{18}$ Briefly, $200 \mu \mathrm{L}$ ZgI-TPGSliposomes were filtered using $0.22 \mu \mathrm{m}$ microporous membrane, then transfered into an ultrafiltration centrifuge tube and centrifuged at $10,000 \mathrm{r} \cdot \mathrm{min}^{-1}$ for $20 \mathrm{~min}$. $100 \mu \mathrm{L}$ ultrafiltrate were taken out and diluted with methanol to $1 \mathrm{~mL}$. The DL and EE were measured using HPLC (WiSys 5000, Welch Technologies, China), according to the 
chromatographic condition as we set before (Unitary C18 (250 mm $\times 4.6 \mathrm{~mm} \times 5 \mu \mathrm{m}$; Welch Technologies); Column temperature $=30^{\circ} \mathrm{C}$; Wavelength $=203 \mathrm{~nm}$; The mobile phase acetonitrile/water $(35 / 65, \mathrm{v} / \mathrm{v})$; Flow rate $=1 \mathrm{~mL} / \mathrm{min})$.

Fourier transform infrared spectroscopy (FTIR, Nicolet 6700; Thermo Fisher, USA) was used to determine the physical status of $\mathrm{ZgI}$ inside the liposomes. The pristine ZgI, physical mixture of ZgI, phosphatidylcholine, cholesterol and TPGS and the freeze dried samples of blank liposomes and ZgI-TPGS-liposomes were detected and compared.

X-ray Diffraction (XRD). The structural properties of samples were obtained using the D8 Focus X-ray diffractometer (Bruker, Germany) with $\mathrm{Cu}-\mathrm{K} \alpha$ radiation. Measurements were performed at a voltage of $40 \mathrm{kV}$ and $40 \mathrm{~mA}$. Samples were scanned from $5^{\circ}$ to $80^{\circ}$, and the scanned rate was $6 \% \mathrm{~min}$.

\section{Stability Studies}

ZgI-TPGS-liposomes were stored at $4^{\circ} \mathrm{C}$ for 3 months. Samples were taken out at $0,1,2$, and 3 months for particle size, PDI, Zeta potential and encapsulation efficiency analysis, respectively.

\section{Cell Culture and Cell Viability Assay}

RAW264.7 cells were cultured in DMEM supplemented containing $10 \%$ fetal bovine serum with $100 \mathrm{U} / \mathrm{mL}$ of penicillin and $100 \mu \mathrm{g} / \mathrm{mL}$ of streptomycin at $37^{\circ} \mathrm{C}$ with $5 \%$ $\mathrm{CO}_{2}$. HSPC-1 cells were cultured in RPMI-1640 containing $10 \%$ fetal bovine serum with $100 \mathrm{U} / \mathrm{mL}$ of penicillin and $100 \mu \mathrm{g} / \mathrm{mL}$ streptomycin, which can support the growth of $\mathrm{CD} 34^{+}$hematopoietic stem cells. Cytotoxicity of ZgI-TPGS-liposomes was assessed by CCK-8 assay. The OD values were estimated by measuring absorbance at $450 \mathrm{~nm}$ in a microplate reader (MK3, Thermo, USA).

\section{Cellular Uptake and Intracellular Localization Analysis}

The fluorescent dye coumarin- 6 was used as a fluorescent probe to investigate the cellular uptake of C-6 or C-6 TPGS liposomes. ${ }^{19}$ The RAW264.7 cells at logarithmic phase were seeded in 96-well plates at a density of $1 \times 10^{4}$ per well. At $24 \mathrm{~h}$ post- seeding, cells were given C-6 or C-6 TPGS liposomes and incubated for $2 \mathrm{~h}$ in the incubator. Then, the supernate was removed and cells were washed thrice with cold PBS and fixed with 4\% paraformaldehyde for $20 \mathrm{~min}$. The DAPI $(100 \mu \mathrm{L})$ were added into each well to stain the cell nucleus. 10 min later, cells were washed thrice with cold PBS. Finally, cells of each group were observed under a fluorescence microscope (CKX53IPC; Olympus, Japan) and the relative fluorescence intensity was measured by accompanying cellsens standard software.

\section{In vitro Release}

The dialysis bag diffusion method was used to investigate the in vitro release of ZgI, ZgI-liposomes and ZgI-TPGSliposomes, which contains the same concentration of $\mathrm{ZgI}$. $\mathrm{ZgI}$ was dissolved in methanol solution, and then three samples were put into the dialysis bags, respectively. The dialysis bags with samples were immersed in PBS solution ( $\mathrm{pH} 7.4$ ) containing $0.5 \%$ Tween-80 (the release medium) at a temperature of $(37 \pm 0.5){ }^{\circ} \mathrm{C}$, shaking at a speed of 100 $\mathrm{r} \cdot \min ^{-1} .1 \mathrm{~mL}$ release medium was taken out at $0,2,4,6$, $8,10,12,14,16,18,20,22$ and $24 \mathrm{~h}$, and filtered using $0.22 \mu \mathrm{m}$ filter membrane. At the same time, equal volume of isothermal release medium was replenished. The $\mathrm{ZgI}$ concentration in the sample was assayed by the above HPLC method, and the cumulative drug release rate (Q) at different time points was calculated according to following formula, and the cumulative release curve was drawn.

$$
Q=\frac{c_{n} V_{0}+\sum^{i=1} n-1 c_{i} V_{i}}{m} \times 100 \%
$$

Where $\mathrm{V}_{0}$ is the total volume of the release medium $(\mathrm{mL}), \mathrm{C}_{\mathrm{i}}$ and $\mathrm{C}_{\mathrm{n}}$ are the drug concentration $\left(\mathrm{mg} \cdot \mathrm{mL}^{-1}\right)$ measure at the $\mathrm{i}-\mathrm{hr}$ and $\mathrm{n}-\mathrm{hr}$ time points, $\mathrm{V}_{\mathrm{i}}$ is the sampling volume $(\mathrm{mL})$, and $\mathrm{m}$ is the total mass of $\mathrm{ZgI}$ in the samples.

\section{Pharmacokinetic Studies of Zgl-TPGS- Liposomes}

Pharmacokinetic study was performed in healthy SD rats. The rats were randomly assigned into three groups $(n=5)$. The pharmacokinetic properties of ZgI-TPGS-liposomes were compared with ZgI-liposomes and ZgI solution. All the samples were intravenously administered at a dose of $20 \mathrm{mg} / \mathrm{kg}$. The blood $(0.3 \mathrm{~mL})$ was collected into a heparinized microtube by retro-orbital puncture at $0,0.083,0.5,1,1.5,2,4,6,8$, 12, 18 and $24 \mathrm{~h}$ after injection. The blood samples obtained were immediately centrifuged at $10,000 \mathrm{rpm}$ for 3 minutes to get the plasma, and $100 \mu \mathrm{L}$ of plasma was mixed with $200 \mu \mathrm{L}$ Ginsenoside $\mathrm{Rg}_{3}(100 \mathrm{ng} / \mathrm{mL})$ as the internal standard, then the mixture was vortexed for $1 \mathrm{~min}$ to mix evenly. The supernatant was collected after centrifugation at 12,000 rpm for 10 
minutes, and mixed with $100 \mu \mathrm{L}$ deionized water for the drug content analysis by HPLC-MS (Agilent 1260UPLC-G6530QTOF MS, USA). The pharmacokinetic parameters were calculated using a PKSolver software.

\section{Pharmacodynamics Study of Zgl-TPGS- Liposomes}

In vitro Pharmacodynamics Study

Cyclophosphamide(CTX) was used to induce hematopoietic stem cells injury in vitro. HSPC-1 cells were seeded in a 96-well plate at a density of $1 \times 10^{5}$ per well. Experimental groups were set with the following conditions: normal control group (NC, saline + RPMI1640), CTX (CTX + RPMI1640), ZgI, ZgI-liposomes and ZgITPGS-liposomes treatment group (CTX + RPMI 1640 supplemented with $10 \mu \mathrm{M} \mathrm{ZgI}$, ZgI-liposomes and ZgITPGS-liposomes, respectively). Except the NC group, cells in other groups were incubated with CTX at a concentration of $1 \mu \mathrm{M}$. After incubation for $36 \mathrm{~h}$, the supernatant of each group was removed, and relevant drugs were added. After treatment for $24 \mathrm{~h}$, the cell viability was assessed by the CCK-8 assay and the apoptosis was detected using Tunel Apoptosis Detection Kit (FITC) and Flow cytometry, respectively.

\section{In vivo Pharmacodynamics Study}

In vivo pharmacodynamics study was performed in healthy KM mice. Mice were injected with CTX $(120 \mathrm{mg} / \mathrm{kg}$ ) normal saline solution intraperitoneally to make myelosuppression model. ${ }^{20}$ In this experiment, $90 \mathrm{KM}$ mice were randomized according to their body weight into 6 experimental groups after 7 days of acclimatization: Normal control (NC, $n=15)$ : Mice were not injected CTX and treated with purified water by oral gavage. Model control group (CTX, $n=15)$ : Mice were injected CTX and treated with purified water by oral gavage. Positive control (G-CSF, $n=$ 15): Mice were injected CTX and treated with G-CSF by subcutaneous injection $(10 \mu \mathrm{g} / \mathrm{kg})$. ZgI-treated groups (ZgI $5 \mathrm{mg} / \mathrm{kg}, n=15)$ : Mice were injected CTX and intravenously treated with ZgI normal saline solution. ZgI-liposomes-treated groups (ZgI-lip, 5mg/ $\mathrm{kg}, n=15)$ : Mice were injected CTX and intravenously treated with $\mathrm{ZgI}$-liposomes normal saline solution. ZgITPGS-liposomes-treated groups (ZgI-TPGS-lip, 5mg/ $\mathrm{kg}, n=15)$ : Mice were injected CTX and intravenously treated with ZgI-TPGS-liposomes normal saline solution.

The CTX was injected one time at the first day of experiment. The purified water were given one time a day for 6 days. The G-CSF, ZgI, ZgI-liposomes and ZgI-TPGS-liposomes were given at the third day according to the above administration method. The body weights in each group were monitored daily for 6 days after CTX injection. At day 6 p.i., blood samples of each group were collected by retro-orbital puncture into heparinized tubes, the leucocyte and neutrophils were assayed by automatic blood cell counting instrument (URIT-3000, Shanghai, China).

The schematic illustration of in vivo and in vitro pharmacodynamics study is shown in Figure 3.

\section{Statistical Analysis}

All the data in this study were analyzed by SPSS 18.0. Data are expressed as mean $\pm \mathrm{SD}$. For values that were normally distributed, direct comparison between two

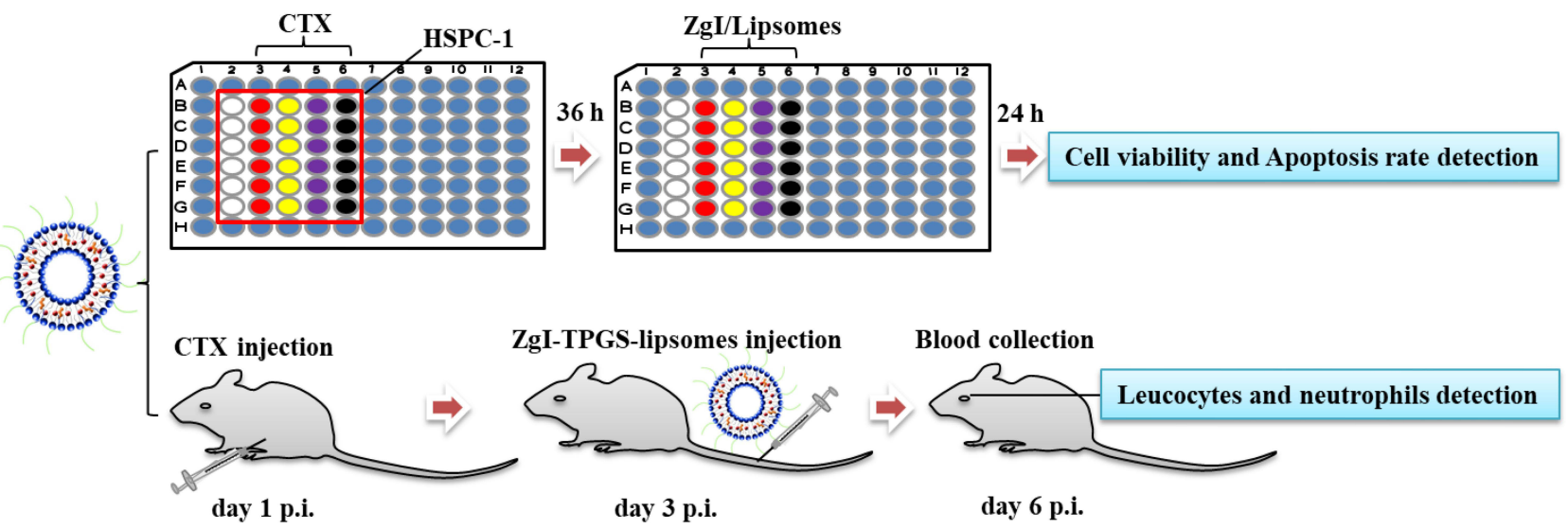

Figure 3 Schematic illustration of in vivo and in vitro pharmacodynamics study of Zgl-TPGS-liposomes. 
groups was conducted by Independent Sample's $T$ test. $P$ value of $<0.05$ was considered statistically significant.

\section{Results}

\section{Determination of $\mathrm{Zgl}$ Content} HPLC Chromatograms and Specificity

Typical HPLC chromatograms of $\mathrm{ZgI}$ in liposomes are shown in Figure 4. Under chromatographic conditions described in the HPLC methods section, $\mathrm{ZgI}$ was eluted at $8.1 \mathrm{~min}$, during the 16 -min run-time, and no significant interfering peaks of liposomes components were observed.

\section{Calibration Curve and Linearity}

Good linearity was observed over the concentration range of $5.0 \sim 250.0 \mu \mathrm{g} / \mathrm{mL}$ between peak-area ratios and $\mathrm{ZgI}$ concentrations in test samples. The regression equation of the calibration curve was $Y=1.3292 X+2.6228$. The correlation coefficient was excellent $\left(r^{2}=0.9998\right)$.

\section{Precision and Accuracy}

Intra- and inter-day precision of the method, expressed as relative standard deviation $(R S D \%)$, are presented in Table 1 . The $R S D$ values ranged from $0.83 \%$ to $1.17 \%$ for intra-day and $0.98 \%$ to $1.47 \%$ for inter-day analysis, indicating excellent precision of the developed method. Accuracy, shown in Table 1 as a relative error $(R E \%)$, varied from $0.86 \%$ to $1.89 \%$ for intra-day and from $0.99 \%$ to $1.32 \%$ for inter-day analysis. The method showed satisfactory accuracy.

\section{Recovery}

Recovery of $\mathrm{ZgI}$ was $101.14 \pm 1.36,98.72 \pm 1.23,99.82$ $\pm 0.58 \%$ at the concentrations of 5,50 , and $250 \mu \mathrm{g} / \mathrm{mL}$, respectively. The average recovery for $\mathrm{ZgI}$ in liposomes was $>98 \%$, with $R S D$ values of $1.34 \%, 1.25 \%$, and $0.58 \%$. The results above indicate that extraction recoveries of $\mathrm{ZgI}$ using methanol are satisfactory and highly reproducible.

\section{Characterization of Zgl-TPGS-Liposomes}

The preparation process of ZgI-TPGS-liposomes is briefly shown in Figure 5A, and the samples were characterized by particle size distribution, SEM, TEM, FTIR and XRD. From the Figure $5 \mathrm{~B}$ we can see that the sample of ZgI-TPGSliposomes is a milky white and translucent liquid, showing a obvious Tyndall phenomenon. Its average particle size is $(97.89 \pm 1.42) \mathrm{nm}$ (Figure 5C), and the mean Zeta Potential and polydispersity index (PDI) was $(-28.65 \pm 0.16) \mathrm{mV}$ and $(0.196 \pm 0.013)$, respectively. The TEM and SEM showed that the ZgI-TPGS-liposomes had a double-layer and spherical or quasi-spherical structure, as shown in Figure 5D (TEM) and Figure 5E (SEM), respectively. In addition, the FTIR analysis (Figure 5F) showed that the characteristic peaks of $\mathrm{ZgI}$ such as $\mathrm{C}-\mathrm{O}$ at $1738 \mathrm{~cm}^{-1}$, asymmetric bending vibration of $\mathrm{CH}_{3}$ at $1466 \mathrm{~cm}^{-1}$ and asymmetric bending vibration of $\mathrm{CH}_{2}$ at $1241 \mathrm{~cm}^{-1}$ were detected, respectively. Compared with the infrared absorption peaks of $\mathrm{ZgI}$ and its physical mixture, the characteristic peaks of ZgI in ZgI-liposomes and ZgI-TPGSliposomes had disappeared, indicating the $\mathrm{ZgI}$ had been loaded in ZgI-liposomes and ZgI-TPGS-liposomes.

The XRD spectrum (Figure 5G) of the $\mathrm{ZgI}$ and its physical mixture showed several distinct crystal diffraction peaks between $5^{\circ}$ and $60^{\circ}$. The liposomes and TPGS modified liposomes caused the disappearance of diffraction peaks at $5^{\circ}$ to $60^{\circ}$ in the XRD spectra of the samples, indicating that the $\mathrm{ZgI}$ crystal had become amorphous.

\section{Drug Loading and Encapsulation Efficiency} The percentage of ZgI loaded in the normal liposomes and TPGS-liposomes were $8.62 \%$ and $9.06 \%$, respectively. And the encapsulation of the normal liposomes was

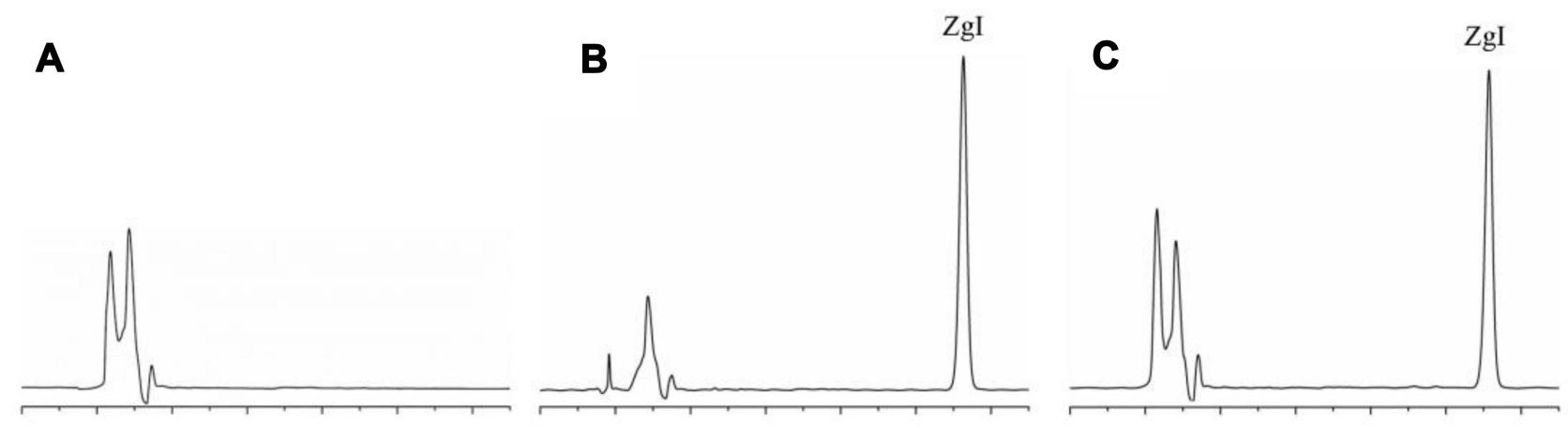

Figure 4 Chromatograms of Zgl in liposomes. (A) negative control (blank liposomes); (B) Zgl standard substance; (C) sample for test (Zgl-liposomes). 
Table I Intra- and Inter-Day Precision and Accuracy of Zgl Quantification

\begin{tabular}{|l|c|c|c|c|}
\hline \multirow{2}{*}{ Concentration $(\mu \mathrm{g} / \mathrm{mL})$} & \multicolumn{2}{|c|}{ Intra-Day $(\mathbf{n = 5 )}$} & \multicolumn{2}{c|}{ Inter-Day (n=3) } \\
\cline { 2 - 5 } & Precision (RSD\%) & Accuracy (RE\%) & Precision (RSD\%) & Accuracy (RE\%) \\
\hline 5 & 0.83 & 1.89 & 1.47 & 0.99 \\
50 & 1.17 & 1.04 & 1.13 & 1.32 \\
250 & 0.92 & 0.86 & 0.98 & 1.06 \\
\hline
\end{tabular}

$85.69 \%$, while that of the TPGS-liposomes reached to $92.34 \%(\mathrm{n}=3)$. As shown in Table 2.

\section{Stability of Zgl-TPGS-Liposomes}

The stability test result (Table 3 ) showed that the appearance, mean particle size and encapsulation efficiency of ZgI-TPGS-liposomes hardly changed during the experiment. We can conclude that ZgI-TPGS-liposomes could keep stable at least 3 months when it was stored at $4{ }^{\circ} \mathrm{C}$.

\section{In vitro Cellular Uptake and Intracellular Localization Analysis}

The Coumarin- 6 is a water-insoluble fluorescent marker, which is usually used to test the cellular uptake efficiency. In this experiment, coumarin-6 was selected as a fluorescent probe instead of $\mathrm{ZgI}$ to investigate the cellular uptake efficiency of common liposomes and TPGSliposomes. As shown in Figure 6A, the green fluorescence was mainly distributed in the cytoplasm. Cells treated by Coumarin-6 (C-6) showed a weak green fluorescence, while the cells treated by C-6-liposomes (C-6-lip) and C-6-TPGS-liposomes (C-6-TPGS-lip) exhibited stronger green fluorescence when compared with C-6 group. The fluorescence intensity of each group was furtherly measured, the result was shown in Figure 6B. From Figure 6B we can see that the C-6-lip and C-6-TPGS-lip exhibited 5.66 and 7.55 -fold stronger fluorescence intensity than C-6 $(P<0.05)$, respectively. Meanwhile, the fluorescence intensity of the C-6-TPGS-lip was 1.33-fold higher than that in the C-6-lip $(P<0.05)$. The result indicated that cells had the best uptake efficiency to the Coumarin-6-TPGSliposomes, which suggested that TPGS modified liposomes could enhance the internalization of drugs in cells.

\section{In vitro Zgl Release Test}

Figure 7 shows the cumulative release rate of pristine $\mathrm{ZgI}$, ZgI-liposomes and ZgI-TPGS-liposomes in 0.5\% Tween80 PBS solution. Compared with the pristine $\mathrm{ZgI}$, drug in ordinary liposomes and TPGS-liposomes exhibited more slowly release rate, showing a sustained release. In the presented result we can see that approximate $50 \%$ of pristine $\mathrm{ZgI}$ was released at $2 \mathrm{~h}$, while the $\mathrm{ZgI}$ release in ZgI-liposomes and ZgI-TPGS-liposomes is only (17.62 \pm $3.26) \%$ and $(8.79 \pm 2.68) \%$ at the same point, respectively $(P<0.01)$. The cumulative drug release of $\mathrm{ZgI}$ reached more than $90 \%$ at $18 \mathrm{~h}$, and it reached to $(94.28$ $\pm 4.24) \%$ at $24 \mathrm{~h}$. At $24 \mathrm{~h}$, the cumulative release of $\mathrm{ZgI}$ was $(91.22 \pm 4.67) \%$ for common liposomes and $(80.33 \pm$ $4.22) \%$ for TPGS-liposomes $(P<0.05)$, respectively. The difference between TPGS liposomes and non-TPGS is statistically significant $(P<0.05)$ from 6 to $24 \mathrm{~h}$. The result suggested that ZgI-TPGS-liposomes exhibited a slower drug release rate than that of ZgI-liposomes.

\section{Pharmacokinetic Profiles of Intravenously Administered Zgl/TPGS}

The free ZgI, ZgI-liposomes and ZgI-TPGS-liposomes were intravenously administered at a dose of $20 \mathrm{mg} / \mathrm{kg}$ from rats tail vein. The plasma concentration-time curve was shown in Figure 8, and the pharmacokinetic parameters was summarized in Table 4. From Figure 8, we can easily find that rats i.v ZgI-TPGS-liposomes had the highest plasma concentration after administration at $0 \mathrm{~h}$, and the initial drug concentration reached to $986.41 \pm$ $39.18 \mathrm{ng} / \mathrm{mL}$. Compared to the ZgI-TPGS-liposomes, the mean plasma concentration of $\mathrm{ZgI}(618.42 \pm 20.34)$ and ZgI-liposomes $(831.49 \pm 35.26)$ was markedly lower at the same time point $(P<0.05)$. The intravenous administration of ZgI-loaded TPGS liposomes resulted in 2.4-fold and 1.7-fold higher plasma concentration of $\mathrm{ZgI}$ than that of free drug $(171.65 \pm 20.31) \mathrm{ng} / \mathrm{mL}$ and ordinary liposomes $(249.35 \pm 43.55) \mathrm{ng} / \mathrm{mL}$, respectively, and the maximum plasma concentration $\left(\mathrm{C}_{\max }\right)$ of ZgI-TPGS-liposomes was substantially high at $405.32 \pm 46.78 \mathrm{ng} / \mathrm{mL}$ at $2 \mathrm{~h}$ after administration. At $24 \mathrm{~h}$, the mean plasma concentration of ZgI-TPGS-liposomes was $58.54 \pm 6.88 \mathrm{ng} / \mathrm{mL}$, which is 5.6-fold and 3.4-fold higher than that of free $\mathrm{ZgI}(10.50 \pm$ $1.03) \mathrm{ng} / \mathrm{mL}$ and $\mathrm{ZgI}-$ liposomes $(17.20 \pm 3.19) \mathrm{ng} / \mathrm{mL}$, 

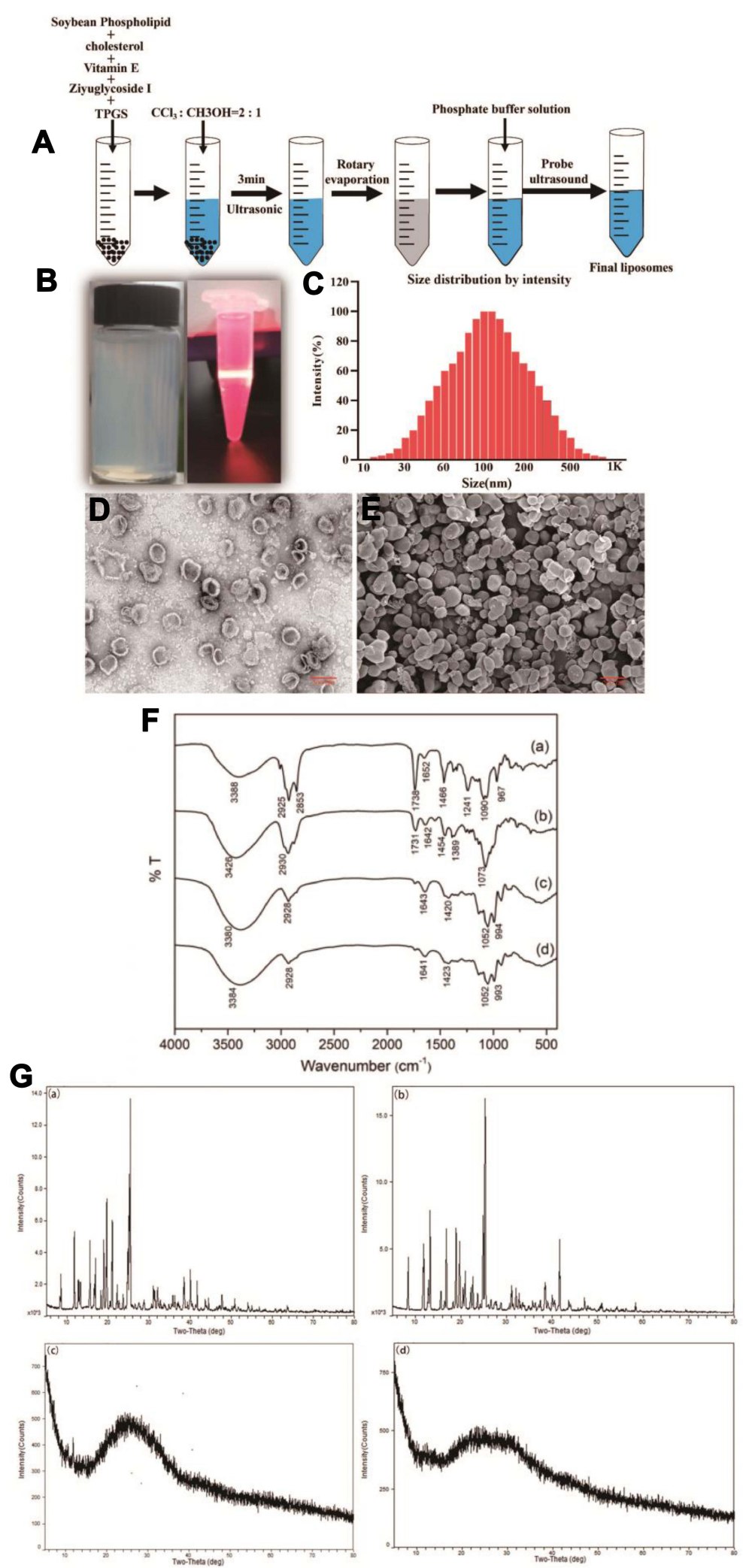

Figure 5 The preparation and characterization of Zgl-TPGS-liposomes. (A) The brief illustration of Zgl-TPGS-liposomes preparation. (B) Actual sample of Zgl-TPGSliposomes. (C) Size distribution. (D) TEM image. (E) SEM image. (F) FTIR spectrum: (a) Zgl. (b) Physical mixture. (c) Zgl-liposomes. (d) Zgl-TPGS-liposomes. (G) XRD spectrum: (a) Zgl. (b) Physical mixture. (c) Zgl-liposomes. (d) Zgl-TPGS-liposomes. 
Table 2 The DL and EE of Zgl-Liposomes and Zgl-TPGS Liposomes $(n=3$, mean $\pm S D)$

\begin{tabular}{|l|c|c|}
\hline Samples & $\begin{array}{c}\text { Zgl Loading } \\
\text { Efficiency/\% }\end{array}$ & $\begin{array}{c}\text { Zgl } \\
\text { Encapsulation } \\
\text { Efficiency/\% }\end{array}$ \\
\hline Zgl-liposomes & $8.62 \pm 0.25$ & $85.69 \pm 2.42$ \\
Zgl-TPGS-liposomes & $9.06 \pm 0.76$ & $92.34 \pm 3.83$ \\
\hline
\end{tabular}

Table 3 Stability Test Result of Zgl-TPGS-Liposomes ( $n=3$, Mean \pm SD)

\begin{tabular}{|l|c|c|c|}
\hline Month & Appearance & $\begin{array}{c}\text { Mean } \\
\text { Particle } \\
\text { Size/nm }\end{array}$ & $\begin{array}{c}\text { Zgl } \\
\text { Encapsulation } \\
\text { Efficiency/\% }\end{array}$ \\
\hline 0 & Translucent liquid & $97.89 \pm 1.42$ & $92.34 \pm 3.83$ \\
1 & Translucent liquid & $95.48 \pm 0.86$ & $92.49 \pm 2.44$ \\
2 & Translucent liquid & $97.24 \pm 0.76$ & $91.87 \pm 2.10$ \\
3 & Translucent liquid & $96.83 \pm 0.81$ & $92.65 \pm 1.56$ \\
\hline
\end{tabular}

respectively. The $\mathrm{AUC}_{0-24} \mathrm{~h}$ of $\mathrm{ZgI-TPGS}-$ liposomes was $38.36 \pm 3.09 \mu \mathrm{g} \cdot \mathrm{mL}^{-1} \cdot \mathrm{h}^{-1}$, it's approximatively 5 -fold and 1.7-fold higher than that of free $\mathrm{ZgI}(8.10 \pm 0.50$ $\left.\mu \mathrm{g} \cdot \mathrm{mL}^{-1} \cdot \mathrm{h}^{-1}\right)$ and ZgI-liposomes $(23.05 \pm 0.36$ $\left.\mu \mathrm{g} \cdot \mathrm{mL}^{-1} \cdot \mathrm{h}^{-1}\right)$, respectively. In addition, the Mean Detention Time (MRT) of ZgI-TPGS-liposomes was markedly prolonged, while the Clearance rate $(\mathrm{CL})$ was markedly reduced when compared to the free $\mathrm{ZgI}(P<0.01)$ and $\mathrm{ZgI}$-liposomes $(P<0.05)$. The pharmacokinetic study results suggested that the TPGS modified liposomes loading Ziyuglycoside I has a long-circulating function, and it promotes the systemic absorption of $\mathrm{ZgI}$.

\section{In vitro and in vivo Pharmacodynamics Study of Zgl-TPGS-Liposomes}

Cytotoxicity of ZgI-TPGS-liposomes was evaluated against Human hematopoietic stem cells (HSPC-1) by the CCK-8 assay. The result showed that the ZgI-TPGSliposomes was non-toxic in HSPC-1 cells at the range of $1 \mu \mathrm{M}$ to $320 \mu \mathrm{M}$ concentration (Figure $9 \mathrm{~A}$ ). In the following experiment, $10 \mu \mathrm{M}$ concentration was chosen to study the protection effect of ZgI-TPGS-liposomes in HSPC-1 cells. In vitro pharmacodynamics experiment, the CTX of $1 \mu \mathrm{M}$ concentration was used to induce HSPC-1 cells injury. After treatment for $24 \mathrm{~h}$, the cell viability and the apoptosis rate were detected, respectively. As shown in Figure 9B, compared to the CTX group, all three drugs could markedly increase the survival rate of CTX injured
HSPC-1 cells, and the ZgI-TPGS-liposomes group has a higher survival rate when compared to the $\mathrm{ZgI}$ and $\mathrm{ZgI}-$ liposomes $(P<0.05)$. The apoptosis rates of each group were furtherly detected by Tunel Apoptosis Detection Kit. The result in Figure 9C displayed that the CTX can induce more than $80 \%$ of HSPC- 1 cells apoptosis.Yet, the apoptosis rate was observably reduced after $\mathrm{ZgI}$ and $\mathrm{ZgI}$ loading liposomes intervention $(P<0.05)$, especially the ZgI-TPGS-liposomes can decrease the apoptosis rate to $10.39 \%$, which exhibited a more significant apoptosis inhibition than $\mathrm{ZgI}$ and $\mathrm{ZgI}$-liposomes $(P<0.05)$. The green fluorescence of apoptosis was observed by fluorescence microscope (Figure 9D). The apoptosis rate of HSPC-1 was furtherly detected using flow cytometry technology (Figure 9E). As expected, CTX exposure significantly increased the apoptosis rate of HSPC-1 cells compared to control group $(\mathrm{p}<0.01)$. The apoptosis rate of HSPC-1 cells can be significantly restrained by ZgITPGS-liposomes and ZgI-liposomes $(\mathrm{p}<0.05)$, and cells treated by ZgI-TPGS-liposomes have a lower apoptosis rate compared to $\mathrm{ZgI}$-liposomes group $(\mathrm{p}<0.05)$. The in vitro pharmacodynamics study indicated that $\mathrm{ZgI}$ has more stronger activity to protect HSPC- 1 cells from CTX induced apoptosis and increase cell viability after loading in TPGS modified liposomes.

Chemotherapy drugs often cause patients weight and hair loss during the clinical treatment. ${ }^{21}$ The similar phenomena was observed in our experiment. When mice were intraperitoneally injected CTX at the dose of $120 \mathrm{mg} / \mathrm{kg}$, we noticed that it caused severe depilation and body weight loss in mice, showing significant adverse reactions. As shown in Figure 10A, compared to the mice in the normal control group, CTX induced a continuous and significant decrease in mice body weight from the third to sixth day $(P<0.05)$. However, mice treated with $\mathrm{ZgI}-$ TPGS-liposomes can maintain a normal body-weight growth, even though the loss of mice body-weight was decreased on the fifth and sixth day, there was no significant difference compared with the normal control group.

To further investigate the effects of ZgI-TPGSliposomes on hemocyte reduction, the counts of leucocyte and neutrophils, the first two types of reduced blood cells during chemoradiotherapy, were detected and analyzed. As shown in Figure 10B and 10C, compared to normal control group, CTX induced a dramatic decline of leucocyte and neutrophils counts $(P<0.01)$. However, the counts of leucocyte and neutrophils were increased after $10 \mu \mathrm{g} / \mathrm{kg}$ of GM-CSF and $5 \mathrm{mg} / \mathrm{kg}$ dose 

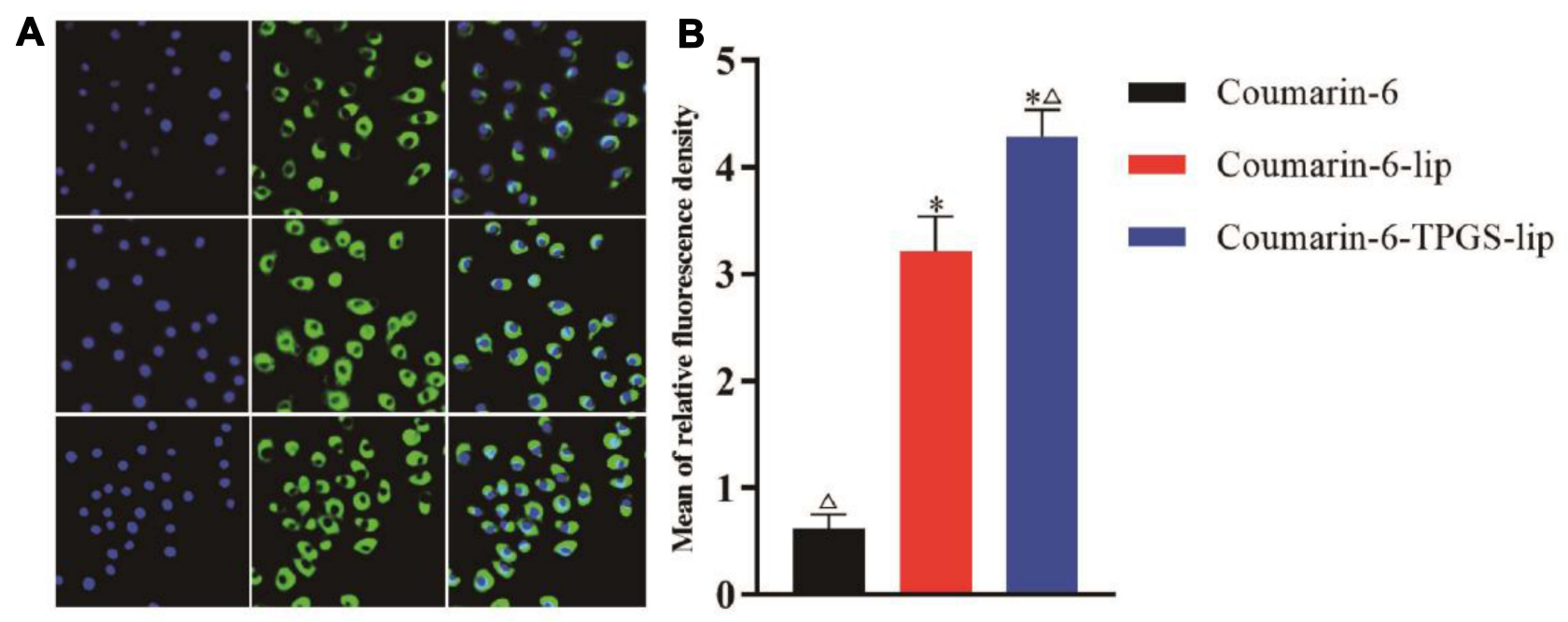

Figure 6 Cellular uptake of coumarin-6-liposomes and TPGS-liposomes in RAW 264.7 cells. (A) Fluorescent images of each group. (B) Comparison of relative fluorescence intensity of each group. Data are presented as mean \pm SD from five independent experiments (vs coumarin-6, ${ }^{*} P<0.05$; vs coumarin-6-lip, ${ }^{\Delta} P<0.05$ ).

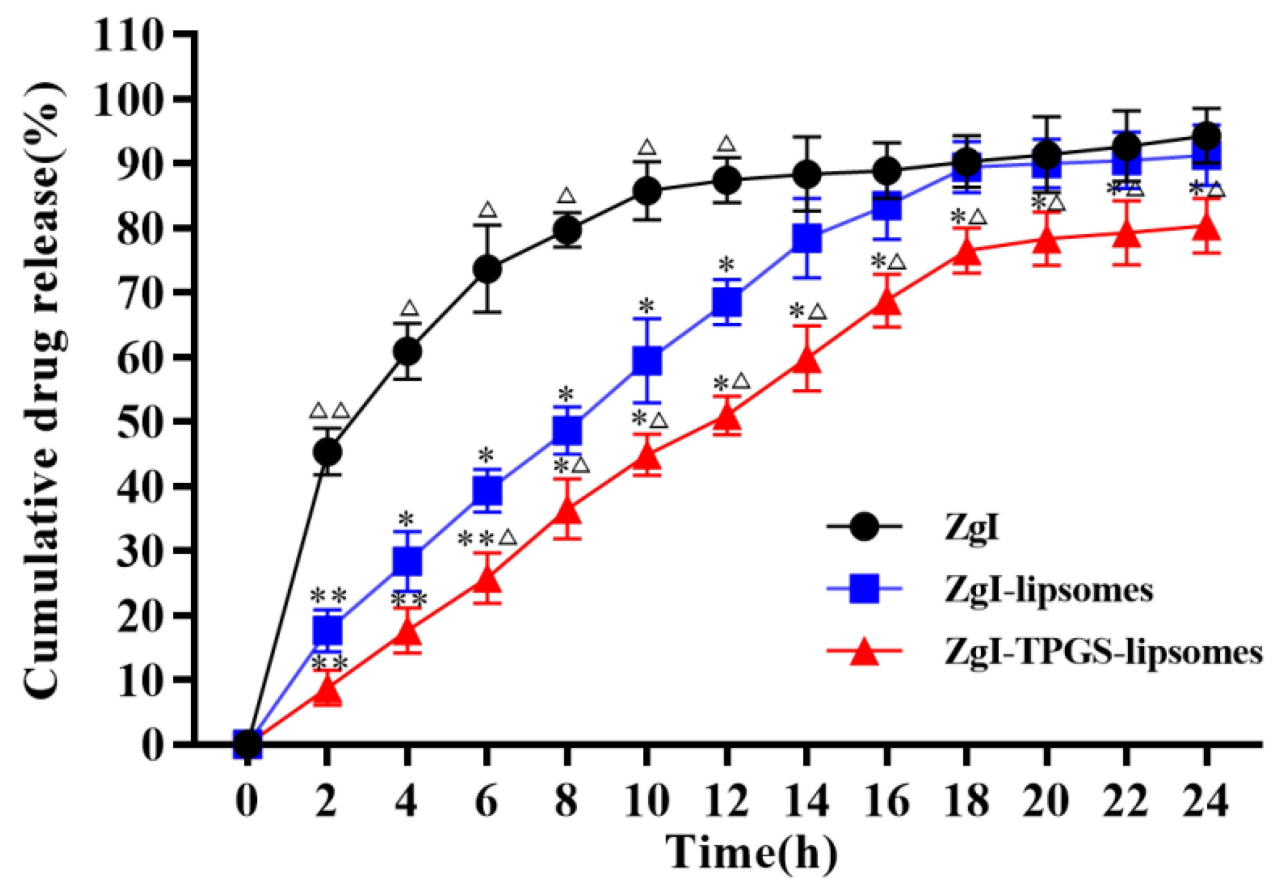

Figure 7 The test result of cumulative $\mathrm{Zgl}$ release. Data are presented as mean $\pm \mathrm{SD}$ from three independent experiments vs $\mathrm{Zgl}$, $* P<0.05$, $* * P<0.0 \mathrm{I}$; vs $\mathrm{ZgI}$-liposomes, ${ }^{\Delta} P<0.05,{ }^{\Delta \Delta} P<0.01$.

of ZgI-TPGS-liposomes treatments $\quad(P<0.01)$. Meanwhile, the counts of leucocyte and neutrophils in mice treated by ZgI-TPGS-liposomes are significant more than that treated by $\mathrm{ZgI}$ and $\mathrm{ZgI}$-liposomes $(P<0.05)$. We can conclude that the pharmacological activity of $\mathrm{ZgI}$ increasing the leucocytes was enhanced after loading in TPGS modified liposomes.
The in vitro and in vivo pharmacodynamics study results indicated that the ZgI-TPGS-liposomes has a remarkable therapeutic effect on CTX induced myelosuppression, which can reduce the apoptosis of HSPC-1 cells and increase cell viability, and inhibit the reduction of leucocyte and neutrophils numbers induced by CTX. 


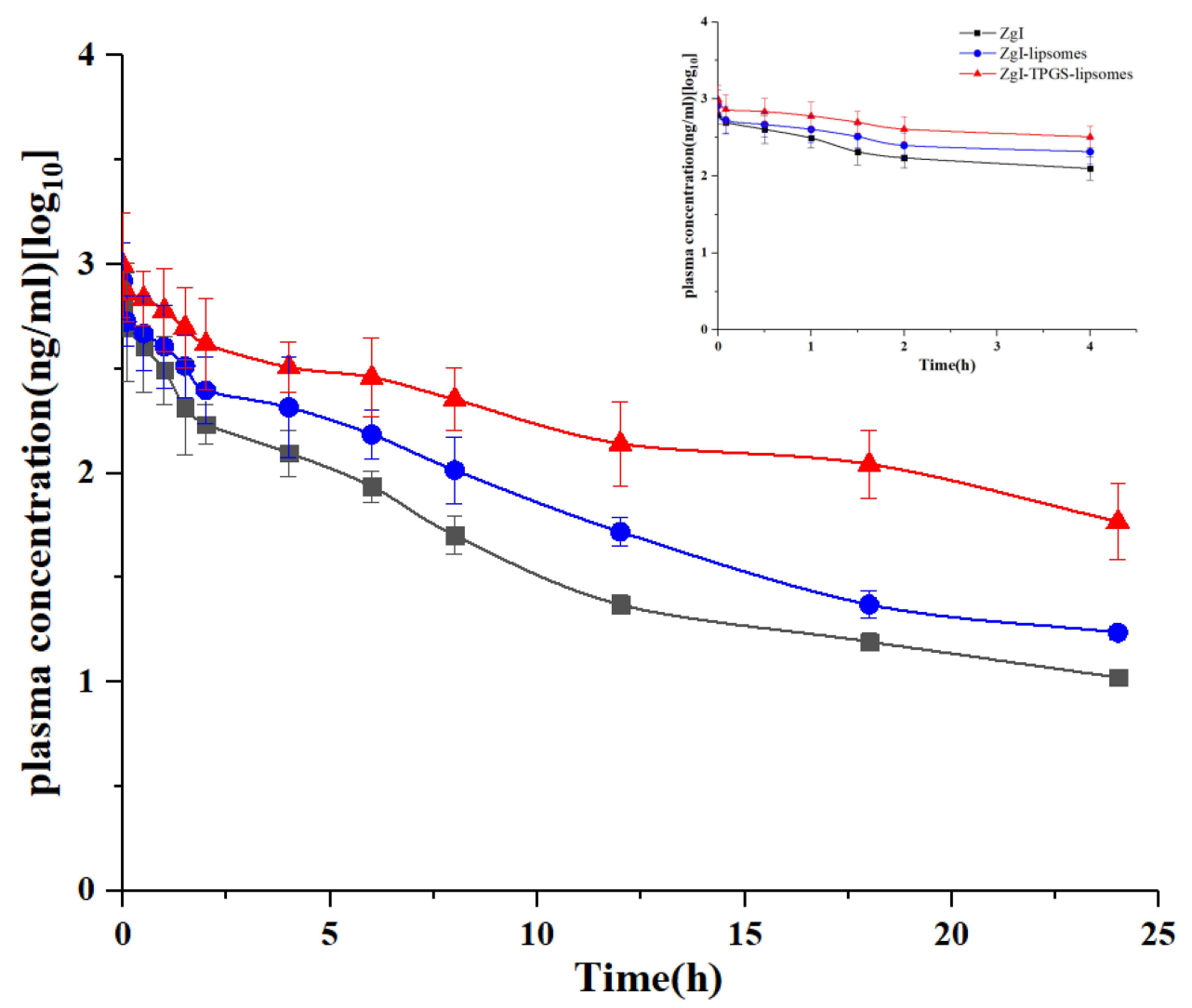

Figure 8 Mean plasma concentration-time curves of Zgl after i.v of a single dose of $20 \mathrm{mg} / \mathrm{kg}$ of Zgl/TPGS. Picture on the top right corner was the plasma concentrationtime curves for $0-4 \mathrm{~h}$ duration (mean $\pm S D, n=6$ ).

\section{Conclusions and Discussion}

In this paper, we successfully developed a TPGS-modified long-circulating liposomes loading $\mathrm{ZgI}$ using a thin film dispersion method, which aimed to enhance the therapy of $\mathrm{ZgI}$ for myelosuppression induced by chemotherapeutics. The average particle size of ZgI-TPGS-liposomes was less than $100 \mathrm{~nm}$, PDI was less than 0.2, and liposomes were spherical vesicles of uniform size. The zeta potential of the liposome solution was less than $-20 \mathrm{mV}$, indicating high stability. The drug encapsulation rate was above $90 \%$, which meets the requirements of liposome preparation, and it showed sustained release in an in vitro release experiment.
Over the past few decades, different approaches have been proposed to manufacture liposomes. ${ }^{22}$ These include lipid film hydration, reverse phase evaporation, ethanol injection, ether injection, detergent removal, etc. Such methods are simple, rapid, and energy- and cost-efficient, ideal for laboratory-scale production and synthesis of smaller particle sizes with narrow particle size distribution. ${ }^{23}$

The reverse phase evaporation method is usually used to encapsulate hydrophilic drugs. ${ }^{24} \mathrm{ZgI}$ has poor water solubility, so this method is not suitable for it. Ethanol injection into an aqueous buffer allows for phase

Table 4 Pharmacokinetic Parameters of Zgl/Zgl-Liposomes/Zgl-TPGS-Liposomes in Rats (Mean \pm SD, $\mathbf{n}=6$ )

\begin{tabular}{|c|c|c|c|}
\hline PK Parameters & ZgI & Zgl-Liposomes & Zgl-TPGS-Liposomes \\
\hline $\operatorname{AUC}_{0-24 h}\left(\mu g \cdot \mathrm{mL}^{-1} \mathrm{~h}^{-1}\right)$ & $8.10 \pm 0.50^{\Delta}$ & $23.05 \pm 0.36^{*}$ & $38.36 \pm 3.09 * * \Delta$ \\
\hline $\mathrm{MRT}_{0-\mathrm{t}}(\mathrm{h})$ & $1.65 \pm 0.045^{\Delta}$ & $3.49 \pm 0.10^{*}$ & $6.82 \pm 0.79 * * \Delta$ \\
\hline$T_{1 / 2}(h)$ & $1.44 \pm 0.12^{\Delta}$ & $3.13 \pm 0.05^{*}$ & $6.63 \pm 0.95^{* * \Delta}$ \\
\hline $\mathrm{CL}\left(\mathrm{mL} \cdot \mathrm{kg}^{-1} \mathrm{~h}^{-1}\right)$ & $184.99 \pm 11.73^{\Delta}$ & $119.82 \pm 13.40^{*}$ & $46.35 \pm 8.67^{* * \Delta \Delta}$ \\
\hline$V_{d}\left(m L k^{-1}\right)$ & $382.02 \pm 39.6 \mathrm{I}^{\Delta}$ & $|453.9| \pm 47.93 *$ & $1760.40 \pm 123.16^{* * \Delta}$ \\
\hline
\end{tabular}

Notes: Data are presented as mean \pm SD from six independent experiments (vs $Z g l, * P<0.05, * * P<0.05$; vs Zgl-liposomes, ${ }^{\Delta} p<0.05,{ }^{\Delta \Delta} p<0.01$.). 

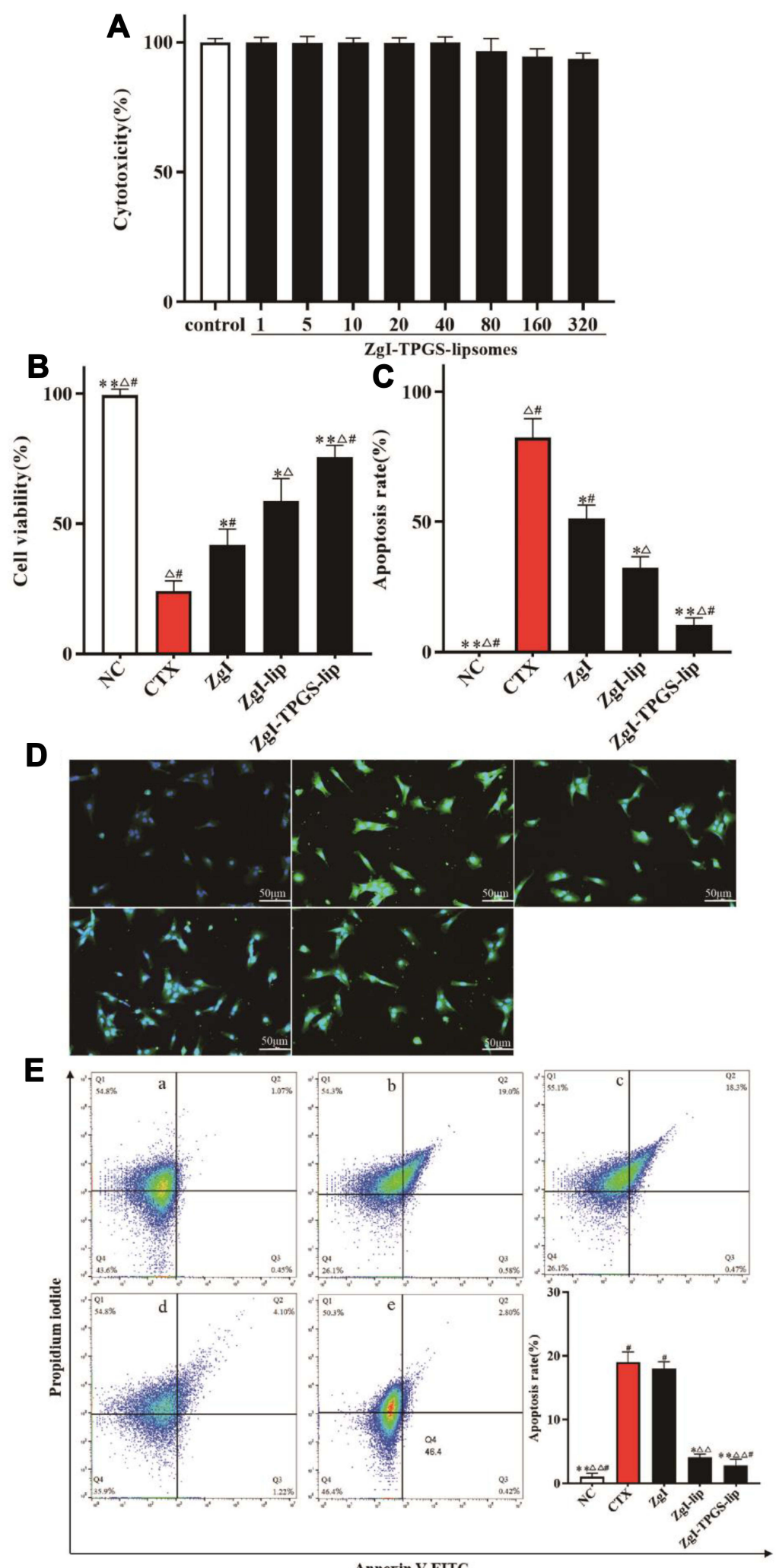

Figure 9 The in vitro study of Zgl-TPGS-liposomes protecting HSPC-I from CTX induced injury. (A). The cytotoxicity of Zgl-TPGS-liposomes in normal HSPC-I cells $(n=3)$. (B). The viability of HSPC-I cells. (C). The apoptosis rate of HSPC-I cells. (D). The green fluorescence of apoptosis photographed by fluorescence microscope; (E). Flow cytometric detection of HSPC-I apoptosis: (a) Normal control group. (b)CTX group. (c) Zgl treatment group. (d) Zgl- liposomes treatment group. (e) Zgl-TPGS-liposomes treatment group.Data are presented as mean $\pm \mathrm{SD}$ from six independent experiments (vs CXT, $* P<0.05$, $* * P<0.05 ;$ vs $Z g \mathrm{gl},{ }^{\Delta} P<0.05$, ${ }_{\Delta \Delta} P<0.01$; vs $Z$ gl-liposomes, ${ }^{\#} P<0.05$.). 

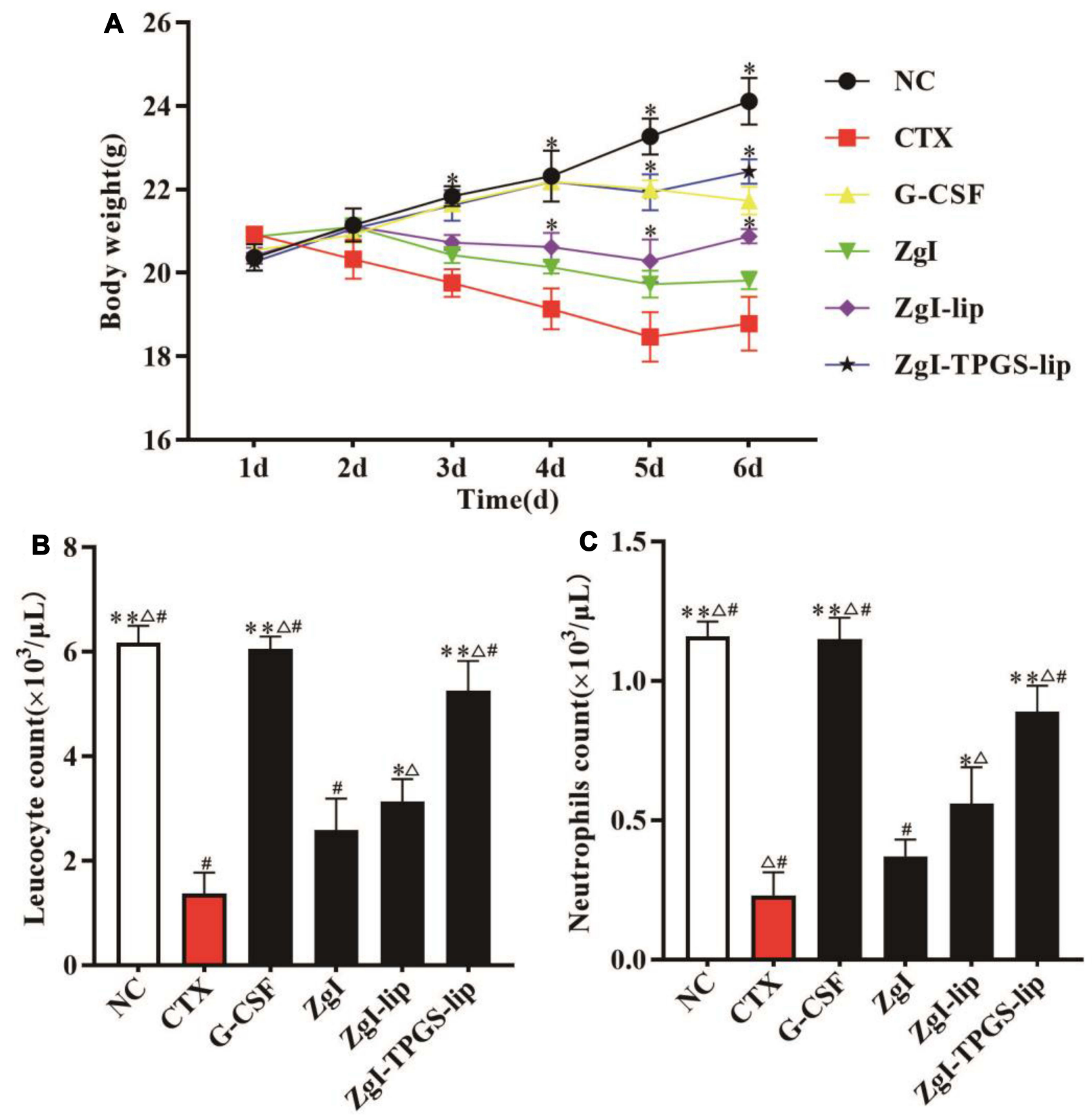

Figure 10 The in vivo treatment of Zgl-TPGS-liposomes on CTX induced myelosuppression. (A). The body weight changes of CTX treated mice after Zgl-TPGS-liposomes treatment. (B). The leucocyte count of CTX treated mice after Zgl-TPGS-liposomes treatment. (C). The neutrophils count of CTX treated mice after Zgl-TPGS-liposomes treatment. Data are presented as mean \pm SD from eight independent experiments (vs CXT, $* P<0.05, * * P<0.05 ;$ vs $\mathrm{Zgl},{ }^{\Delta} P<0.05 ;$ vs $\mathrm{Zgl}-$ liposomes, ${ }^{\#} P<0.05 \mathrm{I}$.).

separation of the lipids that spontaneously assemble into liposomes. This process, however, is usually run in a bulk reactor where the mixing of solutions is not finely controlled, and the separation process of ethanol and water affects the stability of liposomes. ${ }^{25}$ In this experiment, thin-film dispersion method was used to prepare the ZgITPGS-liposomes, which is simple to perform and easy to obtain products with better morphology and particle size.
Due to the excellent biological and physicochemical properties, the TPGS has been widely used for drug delivery and has been approved by FDA as a safe pharmaceutical adjuvant with high biocompatibility. It can serve as an effective P-gp inhibitor for overcoming MDR and increase the uptake of drugs by cells. ${ }^{26}$ What's more, TPGS can modify the surface of liposomes, and improve their stability, prolong the circulation in vivo and increase the 
concentration of drug accumulation, thus enhancing the therapeutic effect of drugs. ${ }^{27}$ These drug delivery advantages of TPGS were also demonstrated in our study. In vitro cellular uptake and intracellular localization study showed that liposomes modified by TPGS could enhance ZgI uptake by RAW264.7 cells. While the cumulative release test and pharmacokinetic study indicated that TPGS liposomes delayed the $\mathrm{ZgI}$ release in vivo and prolonged the retention time in vitro, as the TPGS longcirculating liposomes can significantly reduce the release rate of $\mathrm{ZgI}$ and prolong its circulation time in plasma than that of free $\mathrm{ZgI}$ and ordinary ZgI-liposomes, which is important to improve the bioavailability and therapy of $\mathrm{ZgI}$. According to in vivo and in vitro studies, the surfacecoating is one of the leading factors that significantly affect the circulation time and biodistribution of liposomes following intravenous administration.

TPGS modification enhances the biological activity of ZgI-liposomes, which was convectively confirmed in the pharmacodynamic study. The TPGS liposomes significantly enhanced the therapeutic effect of $\mathrm{ZgI}$ on CTX induced myelosuppression, which can be confirmed in the apoptosis inhibition and cell viability promotion of CTX injured HSPC-1 cells. What's more, the in vivo animal experiment furtherly demonstrated that TPGS liposomes promoted $\mathrm{ZgI}$ increasing the numbers of leucocyte and neutrophils in myelosuppression mice induced by CTX.

In brief, we have successfully formulated TPGS-modified long-circulating liposomes loading ZgI with a sustained drug release and enhanced therapy for myelosuppression, and the prepared formulations of ZgI-TPGS-liposomes were observed to be safe, stable, and therapeutically efficacious in the treatment of myelosuppression. These in vivo and in vitro preliminary investigations reveal the therapeutic potential of these formulations have excellent value for development.

At present, with the continuous discovery of new nanomaterials, technologies of drug delivery are undergoing innovation. Two-dimensional (2D) materials, such as black phosphorus, $^{28-31}$ selenium-coated tellurium, ${ }^{32}$ 2D Boron nanosheets, ${ }^{33}$ 2D Antimonene, ${ }^{34,35}$ 2D MXene $\left(\mathrm{Ti}_{3} \mathrm{C}_{2}\right)^{36}$ and so on, exhibit excellent potential in drug delivery due to their superior physicochemical properties (eg, direct bandgap, strong structural and functional anisotropy, high conductivity and electron transfer capacity), and large surface area-to-volume ratio and easy functionalization. ${ }^{37-39}$ If traditional ordinary materials used for liposome modification such as the TPGS, PLGA, etc. can be combined with these
2D materials, they are expected to be able to achieve the efficacy of synergistic treatment for chronic diseases which needs long-term medication, such as the cancer, diabetes, hypertension, autoimmune disease and so on.

\section{Acknowledgments}

This work was supported by the Guizhou Provincial Research Foundation for Basic Research, China (Grant No. Qiankehejichu[2018]1426), the National Natural Science Foundation of China (No. 81860611), the Science and Technology Support Program of Guizhou province (No. [2021]Genaral410), and the Elite Talent Cultivation Project of Zunyi Medical University.

\section{Disclosure}

The authors report no conflicts of interest for this work.

\section{References}

1. Wei G, Wang Y, Yang G, Wang Y, Ju R. Recent progress in nanomedicine for enhanced cancer chemotherapy. Theranostics. 2021;11 (13):6370-6392. doi: $10.7150 /$ thno. 57828

2. Lawrie TA, Gillespie D, Dowswell T, et al. Long-term neurocognitive and other side effects of radiotherapy, with or without chemotherapy, for glioma. Cochrane Database Syst Rev. 2019;8(8):CD013047CD013047.

3. Zhang Q-Y, Wang F-X, Jia -K-K, Kong L-D. Natural Product Interventions for Chemotherapy and Radiotherapy-Induced Side Effects. Front Pharmacol. 2018;9:1253. doi:10.3389/fphar.20 18.01253

4. Tachi T, Teramachi H, Tanaka K, et al. The impact of outpatient chemotherapy-related adverse events on the quality of life of breast cancer patients. PLoS One. 2015;10(4):e0124169-e0124169. doi:10.1371/journal.pone. 0124169

5. Epstein RS, Basu Roy UK, Aapro M, et al. Cancer Patients' Perspectives and Experiences of Chemotherapy-Induced Myelosuppression and Its Impact on Daily Life. Patient Prefer Adherence. 2021;15:453-465. doi:10.2147/PPA.S292462

6. Turcotte LM, Liu Q, Yasui Y, et al. Temporal Trends in Treatment and Subsequent Neoplasm Risk Among 5-Year Survivors of Childhood Cancer, 1970-2015. JAMA. 2017;317(8):814-824. doi:10.1001/jama.2017.0693

7. Taylor SJ, Duyvestyn JM, Dagger SA, et al. Preventing chemotherapy-induced myelosuppression by repurposing the FLT3 inhibitor quizartinib. Sci Transl Med. 2017;9:402. doi:10.1126/scitranslmed.aam8060

8. Wei Q, Frenette PS. Niches for Hematopoietic Stem Cells and Their Progeny. Immunity. 2018;48(4):632-648. doi:10.1016/j. immuni.2018.03.024

9. Nakamura-Ishizu A, Ito K, Suda T. Hematopoietic Stem Cell Metabolism during Development and Aging. Dev Cell. 2020;54 (2):239-255. doi:10.1016/j.devcel.2020.06.029

10. Im SH, Wang Z, Lim SS, Lee O-H, Kang I-J. Bioactivity-guided isolation and identification of anti-adipogenic compounds from Sanguisorba officinalis. Pharm Biol. 2017;55(1):2057-2064. doi:10.1080/13880209.2017.1357736

11. Xiong Y, Zou Y, Chen L, Xu Y, Wang S. Development and In Vivo Evaluation of Ziyuglycoside I-Loaded Self-Microemulsifying Formulation for Activity of Increasing Leukocyte. AAPS PharmSciTech. 2019;20(3):101. doi:10.1208/s12249-019-1313-3 
12. Yongai Xiong YZ. Promotion of Ziyuglycoside I on white blood cells by autophagy pathway. Chine Herb Med. 2018;49(14):3350-3356.

13. Xiong YA, Yang M. [Effects of sanguisorba tannins and saponins compatibility on pharmacokinetic parameters of catechin, epicatechin and ziyuglycoside in rats]. Zhongguo Zhong Yao Za Zhi. 2016;41 (19):3661-3667. Chinese.

14. Yang C, Wu T, Qi Y, Zhang Z. Recent Advances in the Application of Vitamin E TPGS for Drug Delivery. Theranostics. 2018;8 (2):464-485. doi:10.7150/thno.22711

15. Zhang Z, Tan S, Feng SS. Vitamin E TPGS as a molecular biomaterial for drug delivery. Biomaterials. 2012;33(19):4889-4906. doi:10.1016/j.biomaterials.2012.03.046

16. Guo Y, Chu M, Tan S, et al. Chitosan-g-TPGS nanoparticles for anticancer drug delivery and overcoming multidrug resistance. $\mathrm{Mol}$ Pharm. 2014;11(1):59-70. doi:10.1021/mp400514t

17. Jiang D, Gao X, Kang $T$, et al. Actively targeting $D$ - $\alpha$-tocopheryl polyethylene glycol 1000 succinate-poly(lactic acid) nanoparticles as vesicles for chemo-photodynamic combination therapy of doxorubicin-resistant breast cancer. Nanoscale. 2016;8(5):3100-3118. doi:10.1039/C5NR07724A

18. Tao R, Wang C, Lu Y, et al. Characterization and Cytotoxicity of Polyprenol Lipid and Vitamin E-TPGS Hybrid Nanoparticles for Betulinic Acid and Low-Substituted Hydroxyl Fullerenol in MHCC97H and L02 Cells. Int $J$ Nanomedicine. 2020;15:2733-2749. doi:10.2147/IJN.S249773

19. Jin X, Yang Q, Zhang Y. Synergistic apoptotic effects of apigenin TPGS liposomes and tyroservatide: implications for effective treatment of lung cancer. Int $J$ Nanomedicine. 2017;12:5109-5118. doi:10.2147/IJN.S140096

20. Pan L, Zhang T, Cao H, Sun H, Liu G. Ginsenoside Rg3 for Chemotherapy-Induced Myelosuppression: a Meta-Analysis and Systematic Review. Front Pharmacol. 2020;11:649. doi:10.3389/ fphar.2020.00649

21. Freites-Martinez A, Shapiro J, van den Hurk C, et al. Hair disorders in cancer survivors. J Am Acad Dermatol. 2019;80(5):1199-1213. doi:10.1016/j.jaad.2018.03.056

22. Al-Amin MD, Bellato F, Mastrotto F, et al. Dexamethasone Loaded Liposomes by Thin-Film Hydration and Microfluidic Procedures: formulation Challenges. Int J Mol Sci. 2020;21:5. doi:10.3390/ ijms 21051611

23. Abu Lila AS, Ishida T. Liposomal Delivery Systems: design Optimization and Current Applications. Biol Pharm Bull. 2017;40 (1):1-10. doi:10.1248/bpb.b16-00624

24. Li Y, Xu P, He D, Xu B, Tu J, Shen Y. Long-Circulating Thermosensitive Liposomes for the Targeted Drug Delivery of Oxaliplatin. Int J Nanomedicine. 2020;15:6721-6734. doi:10.2147/ IJN.S250773

25. Franzè S, Selmin F, Rocco P, Colombo G, Casiraghi A, Cilurzo F. Preserving the Integrity of Liposomes Prepared by Ethanol Injection upon Freeze-Drying: insights from Combined Molecular Dynamics Simulations and Experimental Data. Pharmaceutics. 2020;12:6. doi:10.3390/pharmaceutics12060530
26. Bu H, He X, Zhang Z, Yin Q, Yu H, Li Y. A TPGS-incorporating nanoemulsion of paclitaxel circumvents drug resistance in breast cancer. Int $J$ Pharm. 2014;471(1-2):206-213. doi:10.1016/j. ijpharm.2014.05.039

27. Wang HL, Liu SK, Qin YY, Chen YG. Hydroxycamptothecin Stealth Liposomes: containing TPGS as a Novel PEGylated Long-Circulating Coating Material. Adv Mater Res. 2014;886:333-336. doi:10.4028/www.scientific.net/AMR.886.333

28. Meng QA, As B, Dou WC, et al. Biocompatible and biodegradable inorganic nanostructures for nanomedicine: silicon and black phosphorus. Nano Today. 2019;25:135-155. doi:10.1016/j.nantod.2019.02.012

29. Luo M, Fan T, Yun Z, Han Z, Lin M. 2D Black Phosphorus-Based Biomedical Applications. Adv Funct Mater. 2019;29:13. doi:10.1002/ adfm.201808306

30. Xie Z, Peng M, Lu R, et al. Black phosphorus-based photothermal therapy with aCD47-mediated immune checkpoint blockade for enhanced cancer immunotherapy. Light Sci Applications. 2020;9:161. doi:10.1038/s41377-020-00388-3

31. Xing C, Chen S, Qiu M, et al. Conceptually Novel Black Phosphorus/ Cellulose Hydrogels as Promising Photothermal Agents for Effective Cancer Therapy. Adv Healthcare Mater. 2018;7(7):e1701510. doi:10.1002/adhm.201701510

32. Chen S, Xing C, Huang D, et al. Eradication of tumor growth by delivering novel photothermal selenium-coated tellurium nanoheterojunctions. Science Advances. 2020;6(15):eaay6825. doi:10.1126/sciadv.aay 6825

33. Ji X, Kong N, Wang J, et al. A Novel Top-Down Synthesis of Ultrathin 2D Boron Nanosheets for Multimodal Imaging-Guided Cancer Therapy. Adv Mater. 2018; 1803031. doi:10.1002/adma.201803031

34. Tao W, Ji X, Zhu X, et al. Two-Dimensional Antimonene-Based Photonic Nanomedicine for Cancer Theranostics. Advanced Materials. 2018;30(38):e1802061. doi:10.1002/adma.201802061

35. Tao W, Ji X, Xu X, et al. Antimonene Quantum Dots: synthesis and Application as Near-Infrared Photothermal Agents for Effective Cancer Therapy. Angewandte Chemie. 2017;56(39):11896-11900. doi:10.1002/anie.201703657

36. Xing C, Chen S, Xin L, et al. Two-Dimensional MXene (Ti3C2)-Integrated Cellulose Hydrogels: toward Smart Three-Dimensional Network Nanoplatforms Exhibiting Light-Induced Swelling and Bimodal Photothermal/Chemotherapy Anticancer Activity. ACS Appl Mater Interfaces. 2018;10:27631. doi:10.1021/acsami.8b08314

37. Xie Z, Fan T, An J, et al. Emerging combination strategies with phototherapy in cancer nanomedicine. Chem Soc Rev. 2020;49 (22):8065-8087. doi:10.1039/D0CS00215A

38. Chen J, Fan T, Xie Z, et al. Advances in nanomaterials for photodynamic therapy applications: status and challenges. Biomaterials. 2020;237:119827.

39. Tang Z, Kong N, Ouyang J, et al. Phosphorus Science-Oriented Design and Synthesis of Multifunctional Nanomaterials for Biomedical Applications - ScienceDirect. Matter. 2020;2 (2):297-322. doi:10.1016/j.matt.2019.12.007
International Journal of Nanomedicine

\section{Publish your work in this journal}

The International Journal of Nanomedicine is an international, peerreviewed journal focusing on the application of nanotechnology in diagnostics, therapeutics, and drug delivery systems throughout the biomedical field. This journal is indexed on PubMed Central, MedLine, CAS, SciSearch ${ }^{\mathbb{R}}$, Current Contents ${ }^{\mathbb{B}} /$ Clinical Medicine,
Journal Citation Reports/Science Edition, EMBase, Scopus and the Elsevier Bibliographic databases. The manuscript management system is completely online and includes a very quick and fair peer-review system, which is all easy to use. Visit http://www.dovepress.com/ testimonials.php to read real quotes from published authors. 